\title{
PENGEMBANGAN MODUL LUAS DAN KELILING BANGUN DATAR YANG VALID DENGAN PENDEKATAN KONTEKSTUAL BERBASIS KEUNGGULAN LOKAL DI SEKOLAH DASAR
}

\author{
Daswarman, Rieke Alyusfitri \\ Fakultas Keguruan dan Ilmu Pendidikan \\ Universitas Bung Hatta \\ das_warman@yahoo.com \\ Submitted: 16-10-2016, Reviewed: 19-10-2016, Accepted: 09-01-2017
}

\begin{abstract}
Abstrak. Penelitian ini bertujuan untuk menghasilkan modul luas dan keliling bangun datar yang valid di sekolah dasar. Jenis penelitian ini adalah penelitian pengembangan dengan menggunakan model 4D (define, design, develop, dan desseminate). Tahap desseminate tidak dilakukan. Penelitian ini untuk mengetahui apakah modul yang dirancang sudah valid, kemudian divalidasi oleh pakar mengenai materi, penyajian, bahasa dan keterbacaan. Hasil penelitian menunjukkan bahwa modul luas dan keliling bangun datar sudah valid oleh pakar. Oleh sebab itu, disimpulkan bahwa modul luas dan keliling bangun datar di sekolah dasar telah valid.
\end{abstract}

Kata kunci: Modul, Luas dan Keliling, Valid, Sekolah Dasar

\section{PENDAHULUAN}

Matematika merupakan ilmu universal yang mendasari perkembangan teknologi modern, mempunyai peran penting dalam berbagai disiplin dan pengembangan daya pikir manusia. Suherman (2003:15) menjelaskan bahwa matematika adalah metode berpikir logis. Oleh karena itu diperlukan penguasaan matematika yang kuat sejak dini termasuk di Sekolah Dasar (SD). Karso (2009:1.5) menyatakan bahwa matematika bagi siswa SD berguna untuk kepentingan hidup pada lingkungannya, untuk mengembangkan pola pikirnya, dan untuk mempelajari ilmu-ilmu yang kemudian. Mata pelajaran matematika perlu diberikan mulai dari SD untuk membekali siswa dengan kemampuan berpikir logis, analitis, sistematis, kritis, dan kreatif, serta kemampuan bekerjasama.

Muhsetyo (2009:1.26) menyatakan bahwa pembelajaran matematika adalah proses pemberian pengalaman belajar kepada peserta didik melalui serangkaian kegiatan yang terencana sehingga peserta didik memperoleh kompetensi tentang bahan matematika yang dipelajari. Kompetensi tersebut diperlukan agar siswa dapat memiliki kemampuan memperoleh, mengelola, dan memanfaatkan informasi untuk bertahan hidup pada keadaan yang selalu berubah, tidak pasti, dan kompetitif. Heruman (2007:2) menyatakan bahwa tujuan akhir pembelajaran matematika d Sekolah Dasar (SD) yaitu 
agar siswa terampil menggunakan konsep matematika dalam kehidupan sehari-hari.

Ada beberapa kendala dalam pembelajaran matematika, diantaranya penerapan teacher centered. Pola teacher centered mengakibatkan banyaknya dominasi guru dalam pembelajaran. Dalam pembelajaran terkadang guru juga melupakan kemampuankemampuan matematika yang seharusnya dimiliki siswa. NCTM (1998) menyatakan kemampuan-kemampuan matematika yaitu problem solving (kemampuan pemecahan masalah), reasoning and proof (kemampuan penalaran dan pembuktian), communication (kemampuan komunikasi), connection (kemampuan koneksi), dan representation (kemampuan representasi). Pola teacher centered ini masih banyak terjadi dalam pembelajaran matematika SD di kota Padang. Dari beberapa SD Mitra PPL PGSD FKIP Universitas Bung Hatta, 75 \% SD masih menggunakan pola ini. Pola teacher centered yang masih mendominasi dalam pembelajaran matematika di SD, mengakibatkan konstruksi pengetahuan siswa kurang, selain itu pemanfaatan potensi keunggulan lokal yang bisa dijadikan sumber belajar kurang maksimal. Pembelajaran matematika yang dilakukan di SD masih belum dikaitkan dengan kehidupan sehari-hari. Hal ini disebabkan karena belum adanya modul matematika yang mendukung pelajaran dan belum dimasukkannya keunggulan lokal dalam pembelajaran matematika.

Pembelajaran matematika perlu dikaitkan dengan kehidupan sehari-hari (kontekstual). Rusman (2011:187) menyatakan bahwa pembelajaran kontekstual adalah usaha untuk membuat siswa aktif dalam memompa kemampuan diri tanpa merugi dari segi manfaat, sebab siswa berusaha mempelajari konsep sekaligus menerapkan dan mengaitkannnya dengan dunia nyata. Sementara itu, Johnson (2007:35) menyatakan bahwa pembelajaran dan pengajaran kontekstual melibatkan para siswa dalam aktivitas penting yang membantu mereka mengaitkan pelajaran akademis dengan konteks kehidupan nyata yang mereka hadapi. Lebih lanjut Trianto (2007:103) menegaskan bahwa pembelajaran kontekstual (contextual Teaching and Learning) adalah konsep belajar yang membantu guru mengaitkan antara materi yang diajarkannya dengan situasi dunia nyata siswa dan mendorong siswa membuat hubungan antara pengetahuan yang dimiliknya dengan penerapannnya dalam kehidupan sehari-hari, dengan melibatkan tujuh komponen utama pembelajaran kontekstual, yakni konstruktivisme (constructivism), bertanya (questioning), inkuiri (inquiry), masyarakat belajar (learning community), pemodelan (modelling), dan penilaian autentik (authentic assesment). 
Dengan pembelajaran kontestual siswa akan belajar mandiri dengan mengaitkan pelajaran dengan kehidupan sehari-hari.

Selain pola pembelajaran matematika di SD, masih ada kendala yang lain yaitu belum adanya modul yang terkait dengan pembelajaran matematika. Menurut Russel dalam Wena (2013:230), modul sebagai suatu paket pembelajaran yang berisi satu unit konsep tunggal. Sedangkan menurut Walter Dick dan Lou Cary dalam Wena (2013:231), modul diartikan sebagai unit pembelajaran berbentuk cetak. Penggunaan Modul akan membuat siswa belajar secara mandiri. Supaya lebih menarik, modul perlu diperkaya dengan keunggulan lokal. Modul yang berbasis keunggulan lokal ini membuat siswa lebih menyenangkan dalam pembelajaran matematika. Asmani (2012:29) menyatakan keunggulan lokal adalah segala sesuatu yang menjadi ciri khas kedaerahan yang mencakup aspek ekonomi, budaya, teknologi, informasi, komunikasi dan ekologi. Keunggulan lokal harus dikembangkan dari potensi daerah. Potensi daerah merupakan potensi sumber daya spesifik yang dimiliki oleh suatu daerah. Pada modul matematika ini digunakan beberapa keunggulan lokal baik dari seni budaya, permainan dan makanan tradisional.

\section{METODE PENELITIAN}

Metode penelitian yang penulis lakukan adalah metode penelitian dan pengembangan. Sugiyono (2008:407) menyatakan bahwa metode penelitian dan pengembangan adalah metode penelitian yang digunakan untuk menghasilkan produk tertentu, dan menguji kefektifan produk tersebut. Lebih lanjut Trianto (2011:189) menjelaskan bahwa model 4-D terdiri dari 4 tahap pengembangan, yaitu define, design, develop, dan desseminate atau diadaptasikan menjadi model 4-P, yaitu pendefinisian, perancangan, pengembangan, dan penyebaran. Penelitian dilakukan mulai bulan Februari 2016 sampai dengan bulan Agustus 2016. Tempat Penelitian di Sekolah Dasar Negeri 14 Kota Padang Provinsi Sumatera Barat.

Data pada penelitian ini diambil dengan menggunakan lembar validasi modul yang divalidasi oleh 2 orang pakar matematika. Selanjutnya lembar validasi diolah untuk mengetahui apakah modul sudah valid atau belum. Jika belum valid maka modul bisa diperbaiki sesuai saran-saran dari validator. 


\section{HASIL DAN PEMBAHASAN}

Untuk mendapatkan modul yang valid, dilakukan beberapa tahap sesuai dengan model 4-D yang telah dikamukakan di atas. Hasil yang diperoleh pada masing-masing tahapan dapat diuraikan sebagai berikut.

\section{a. Pendefinisian (define)}

Pada tahap ini dilakukan langkah-langkah seperti analisis silabus dan analisis literatur. Hasil yang diperoleh pada masing-masing langkah tersebut adalah sebagai berikut.

\section{1) Analisis Silabus}

Analisis silabus dilakukan untuk melihat apakah materi yang diajarkan sudah sesuai dengan kompetensi yang diharapkan. Berdasarkan hasil dari analisis silabus diketahui bahwa Standar Kompetensi (SK) dari mata pelajaran ini adalah menghitung keliling, luas persegi dan persegi panjang, serta penggunaannya dalam pemecahan masalah, menggunakan konsep keliling dan luas bangun datar sederhana dalam pemecahan masalah, menghitung luas bangun datar sederhana dan menggunakannya dalam pemecahan masalah.

\section{2) Analisis Literatur}

Kegiatan menganalisis literatur merupakan kegiatan yang dilakukan untuk mengumpulkan bahan yang terkait dengan perancangan modul. Struktur ciri khas suatu modul merupakan hal penting dalam perancangan.

\section{b. Perancangan (design)}

Pada tahap ini peneliti merancang modul pada pembelajaran matematika SD. Modul ini dirancang agar siswa terlibat aktif dalam melakukan penemuan-penemuan terhadap konsep yang dipelajarinya. Berdasarkan analisis-analisis yang dilakukan pada tahap pendefinisian, maka dirancanglah modul pembelajaran matematika SD. Berikut ini diuraikan karakteristik modul yang dirancang.

1) Cover Modul

Cover didesain dengan background berwarna biru yang terdapat beberapa konsep bangun datar. Hal ini dilakukan agar siswa memiliki sedikit gambaran mengenai mata pelajaran ini dengan melihat covernya. Judul yang terdapat pada cover adalah "Pembelajaran Pengukuran Luas dan Keliling Bangun Datar di SD". Judul ini memberikan identitas dari modul yang dirancang. Judul pada cover menggunakan jenis 
tulisan Times New Roman berukuran 28, 18, 24. Contoh penyajian cover dapat dilihat pada gambar 1 .

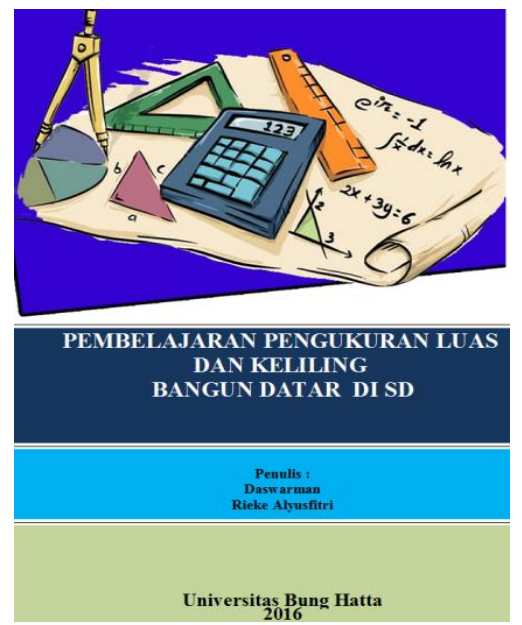

Gambar 1. Cover modul

2) Kata Pengantar

Kata pengantar berisi tentang ucapan syukur dan tujuan penulis merancang modul dengan menggunakan kata-kata yang tidak formal dan mudah dipahami siswa. Judul kata pengantar menggunakan huruf Time New Roman ukuran 18 dan kata-kata di dalam kata pengantar menggunakan huruf yang sama dengan ukuran 14. Contoh dari kata pengantar pada modul Pengukuran Luas dan Keliling Bangun Datar terdapat pada gambar 2.

\section{IATA PENGANTAR}

Puji syukur kehadirat Allah Swt yang telah melimpahkan rahmat dan karunia-Nya sehingga penulis dapat menyelesaikan modul Pengukuran Luas dan Keliling Bangun Datar di SD.

Melalui modul ini penulis menyajikan pembelajaran matematika yang menarik bagi agar dapat memahami materi dengan

Gambar 2. Kata Pengantar Modul

3) Daftar Isi

Daftar isi dibuat dengan jelas agar siswa mudah mencari posisi/ halaman materi yang diinginkan. Kata daftar isi menggunakan huruf Time New Roman ukuran 14 dan pengetikan dari daftar isi menggunakan huruf yang sama dengan ukuran 12. Contoh daftar isi terdapat pada gambar 3. 


\section{DAFTAR ISI}

KATA PENGANTAR i i

DAFTAR ISI ii

PEMBELAJARAN KELILING DAN LUAS BANGUN DATAR DI SD

\begin{tabular}{lll} 
A. Pengantar & 1 \\
B. Tujuan Pembelajaran & & 1 \\
C. Materi Pembelajaran & & 2 \\
1. Persegi & & \\
1.1 Pengertian Persegi & & \\
1.2 Keliling Persegi & & \\
1.3 Luas Persegi & & \\
\hline
\end{tabular}

Gambar 3. Daftar Isi

4) Materi

Materi pada modul ini dikembangkan dengan adanya tujuan pembelajaran agar siswa lebih memahami maksud materi yang akan dibahas. Cuplikan tujuan pembelajaran yang diberikan kepada siswa bisa dilihat pada gambar 4 .

\section{B. Tujuan Pembelajaran}

Setelah mempelajari bab ini, Anda diharapkan akan mampu menjelaskan tentang keliling dan luas dari persegi panjang, jajar genjang, layang-layang, trapesium, dan segitiga. Untuk membantu Anda menguasai kemampuan tersebut, maka pada pembahasan bab ini akan diuraikan dalam Standar Kompetensi (SK) dan Kompetensi Dasar (KD) dibawah ini :

1. Menghitung keliling, luas persegi dan persegi panjang serta penggunaanya dalam pemecahan masalah.

1.1. Menghitung keliling persegi dan persegi panjang

Gambar 4. Tujuan Pembelajaran

5) Contoh Soal

Pada contoh soal tedapat soal-soal yang relevan dengan materi yang disajikan.

Contoh soal disajikan menggunakan bahasa yang mudah dipahami sehingga mampu 
menfasilitasi siswa untuk belajar mandiri. Cuplikan penyajian dari contoh soal yang terdapat pada modul bisa dilihat pada gambar 5 .

\section{Contoh Soal}

1. Hitunglah keliling sebuah persegi yang panjang sisinya $5 \mathrm{~cm}$.

Jawaban :

Sisi persegi $=5 \mathrm{~cm}$, maka

Keliling persegi $=4 \mathrm{x}$ sisi

$$
\begin{aligned}
& =4 \times 5 \mathrm{~cm} \\
& =20 \mathrm{~cm}
\end{aligned}
$$

Jadi keliling dari suau persegi adalah $20 \mathrm{~cm}$.

2. Jika diketahui keliling suatu persegi $48 \mathrm{~cm}$. Tentukan sisi dari bangun persegi tersebut? Jawaban :

Keliling persegi $=48 \mathrm{~cm}$, maka sisi $=\ldots$

\section{Gambar 5. Contoh Soal Modul}

6) Daftar Rujukan

Daftar rujukan berada pada akhir modul berisi acuan yang digunakan pada saat penulisan modul. Daftar rujukan berguna untuk memberi tahu siswa dari mana sumber Modul ini didapatkan. Salah satu cuplikan dari daftar rujukan yang terdapat pada Modul bisa dilihat pada gambar 6.

\section{DAFTAR RUJUKAN}

Pujiati, Sigit TG. 2009. Pembelajaran Pengukuran Luas Bangun Datar dan Volume Bangun Ruang di SD. Yogyakarta : Pusat Pengembangan dan Pemberdayaaan Pendidik dan Tenaga Kependidikan (PPPPTK) Matematika.

Herawati, Susi. 2010. Pembelajaran Matematika Kelas Lanjut di Sekolah Dasar. Padang : Bung Hatta University Press.

Gambar 6. Daftar Rujukan 


\section{c. Pengembangan (develop)}

\section{Tahap Validasi}

Modul yang telah dirancang selanjutnya divalidasi oleh validator. Validasi Modul dilakukan oleh 2 orang validator. Modul dinyatakan valid setelah dilakukan beberapa kali diskusi dan perbaikan. Kegiatan validasi pertama dilakukan pada tanggal 23 Mei 2016 pada pakar matematika dan pakar bahasa. Rangkuman dari hasil diskusi dengan validator dapat dilihat pada Tabel 1.

Tabel 1. Rangkuman Saran Validator

\begin{tabular}{|c|c|c|}
\hline No & Nama & Saran \\
\hline 1 & Syafni Gustina Sari, M.Pd & $\begin{array}{l}\text { Pemberian nama/ identitas pada gambar harus jelas. } \\
\text { penyajian konsep hendaknya dapat mengajak siswa untuk } \\
\text { melakukan penemuan. } \\
\text { Cek lagi pengetikan kalimat pada Modul ! } \\
\text { Format penulisan perlu diperbaiki. } \\
\text { Cek lagi penggunaan bahasa! } \\
\text { Cek lagi teknik penataan gambar pada Modul! } \\
\text { Cover pada Backround lebih menarik }\end{array}$ \\
\hline 2 & Ira Rahmayuni Jusar, M.Pd & $\begin{array}{l}\text { Cek lagi pengetikan, } \\
\text { Penulisan identitas gambar tidak konsisten, } \\
\text { Tambahkan contoh soal } \\
\text { Beri arsiran pada gambar agar terlihat jenis bangun datar }\end{array}$ \\
\hline
\end{tabular}

Perbaikan yang dilakukan disesuaikan dengan saran yang diberikan dari validator. Kegiatan validasi selanjutnya dilakukan pada waktu yang berbeda (disesuaikan dengan kesediaan validator). Kegiatan ini dilakukan untuk berdiskusi dengan validator seputar perbaikan yang telah dilakukan. Diskusi yang dilakukan dengan validator terkait dengan perbaikan yang telah dilakukan mendapatkan hasil bahwa modul telah valid dan dapat digunakan pada uji coba.

Data angket hasil penilaian validator dideskripsikan dan dianalisis secara kualitatif dan kuantitatif. Berikut diuraikan hasil validasi Modul yang telah dirancang.

a) Aspek Materi dalam Modul

Hasil validasi aspek materi dalam Modul dapat terlihat pada Tabel 2. Pada Tabel 2 terlihat bahwa rerata hasil penilaian validator terhadap modul yang dirancang berkisar $>$ 3,20. Menurut Muliyardi (2006: 82) bila rerata hasil validasi bernilai > 3,20 maka perangkat pembelajaran dikategorikan sangat valid. Hasil validasi modul menggambarkan bahwa materi yang disajikan telah sesuai dengan kompetensi yang ingin dicapai. Materi telah dirumuskan berdasarkan langkah-langkah pembuatan modul 
sehingga memberikan kesempatan bagi siswa dalam menemukan sendiri konsep yang dipelajarinya. Hal ini didukung dengan penyajian materi yang sistematis dan adanya contoh soal yang relevan dengan materi yang disajikan. Hasil Validasi Aspek Materi dalam Modul dapat dilihat pada tabel 2.

Tabel 2. Hasil Validasi Aspek Materi dalam Modul

\begin{tabular}{|c|c|c|c|c|}
\hline \multirow{2}{*}{ Aspek yang divalidasi } & \multicolumn{2}{|c|}{ Validator } & \multirow{2}{*}{ Jml } & \multirow{2}{*}{ Rerata } \\
\hline & 1 & 2 & & \\
\hline 1 & 2 & 3 & 4 & 5 \\
\hline $\begin{array}{l}\text { Materi yang disajikan telah sesuai } \\
\text { dengan kompetensi yang ingin } \\
\text { dicapai }\end{array}$ & 5 & 2 & 7 & 3,5 \\
\hline $\begin{array}{l}\text { Konsep-konsep yang diuraikan } \\
\text { pada materi dipertegas dengan } \\
\text { gambar }\end{array}$ & 5 & 3 & 8 & 4 \\
\hline $\begin{array}{l}\text { Penyajian materi telah memberikan } \\
\text { kesempatan bagi siswa dalam } \\
\text { menemukan sendiri konsep dan } \\
\text { prinsip yang dipelajari }\end{array}$ & 4 & 4 & 8 & 4 \\
\hline 1 & 2 & 3 & 4 & 5 \\
\hline $\begin{array}{l}\text { Materi telah disajikan dengan } \\
\text { urutan yang sistematis }\end{array}$ & 4 & 4 & 8 & 4 \\
\hline $\begin{array}{l}\text { Materi telah dirumuskan } \\
\text { berdasarkan langkah-langkah } \\
\text { pembuatan modul }\end{array}$ & 5 & 2 & 7 & 3,5 \\
\hline $\begin{array}{l}\text { Contoh soal, latihan terbimbing dan } \\
\text { latihan mandiri relevan dengan } \\
\text { materi yang disajikan. }\end{array}$ & 4 & 5 & 9 & 4,5 \\
\hline
\end{tabular}

b) Aspek Penyajian Pada Modul

Hasil validasi aspek penyajian dalam Modul dapat terlihat pada Tabel 3 berikut.

Tabel 3. Hasil Validasi Aspek Penyajian dalam Modul

\begin{tabular}{|l|c|c|c|c|}
\hline \multicolumn{1}{|c|}{ Aspek yang divalidasi } & \multicolumn{2}{|c|}{ Validator } & \multirow{2}{*}{ Jml } & Rerata \\
\cline { 2 - 5 } & $\mathbf{1}$ & $\mathbf{2}$ & & $\mathbf{4}$ \\
\hline $\begin{array}{l}\text { Kompetensi utama dan khusus serta } \\
\text { petunjuk modul telah disajikan secara } \\
\text { jelas }\end{array}$ & 5 & 3 & 8 & 4 \\
\hline $\begin{array}{l}\text { Secara penulisan konsep dan istilah } \\
\text { rumus yang ada pada modul telah } \\
\text { disajikan dengan jelas }\end{array}$ & 5 & 3 & 8 & 4 \\
\hline $\begin{array}{l}\text { Penyajian materi telah membahasakan } \\
\text { gagasan yang ingin disampaikan }\end{array}$ & 4 & 5 & 9 & 4,5 \\
\hline $\begin{array}{l}\text { Penyajian materi telah memunculkan } \\
\text { proses pembentukan dan pemahaman }\end{array}$ & 4 & 4 & 8 & 4 \\
\hline
\end{tabular}




\begin{tabular}{|l|c|c|c|c|}
\hline konsep & & & & \\
\hline $\begin{array}{l}\text { Penyajian materi telah melibatkan } \\
\text { siswa secara aktif menemukan konsep } \\
\text { secara mandiri }\end{array}$ & 5 & 3 & 8 & 4 \\
\hline $\begin{array}{l}\text { Penyajian gambar jelas dengan warna } \\
\text { yang bervariasi }\end{array}$ & 4 & 4 & 8 & 4 \\
\hline $\begin{array}{l}\text { Modul telah menyajikan perumusan } \\
\text { masalah yang akan menjadi fokus bagi } \\
\text { siswa dalam melakukan penemuan- } \\
\text { penemuan }\end{array}$ & 5 & 2 & 7 & 3,5 \\
\hline
\end{tabular}

Pada Tabel 3 terlihat bahwa rerata hasil penilaian validator terhadap Modul yang dirancang berkisar > 3,20. Menurut Muliyardi (2006: 82) bila rerata hasil validasi bernilai > 3,20 maka perangkat pembelajaran dikategorikan sangat valid. Hasil validasi Modul menggambarkan bahwa unsur-unsur Modul seperti standar kompetensi, kompetensi dasar dan petunjuk penggunaan disajikan secara jelas.

Penyajian materi telah melibatkan siswa secara aktif untuk menemukan konsep secara mandiri. Selain itu, penyajian gambar jelas dengan warna yang bervariasi.

c) Aspek bahasa dan keterbacaan pada Modul

Hasil validasi aspek bahasa dan keterbacaan dalam Modul dapat terlihat Tabel 4 berikut.

Tabel 4. Aspek Bahasa dan Keterbacaan dalam Modul

\begin{tabular}{|l|c|c|c|c|}
\hline \multirow{2}{*}{ Aspek yang divalidasi } & \multicolumn{2}{|c|}{ Validator } & \multirow{2}{*}{ Jml } & Rerata \\
\cline { 2 - 5 } \multicolumn{1}{|c|}{ 1 } & $\mathbf{2}$ & $\mathbf{3}$ & $\mathbf{5}$ & $\mathbf{6}$ \\
\hline $\begin{array}{l}\text { Kalimat yang digunakan telah } \\
\text { sesuai dengan kaidah bahasa } \\
\text { Indonesia }\end{array}$ & 4 & 4 & 8 & 4 \\
\hline $\begin{array}{l}\text { Kalimat yang digunakan } \\
\text { melibatkan kemampuan berfikir } \\
\text { logis siswa }\end{array}$ & 5 & 3 & 8 & 4 \\
\hline $\begin{array}{l}\text { Struktur kalimat telah sesuai } \\
\text { dengan tingkat pemahaman siswa }\end{array}$ & 4 & 4 & 8 & 4 \\
\hline $\begin{array}{l}\text { Bentuk dan ukuran huruf pada } \\
\text { Modul telah sesuai dengan } \\
\text { kapasitas keterbacaan siswa }\end{array}$ & 5 & 2 & 7 & 3,5 \\
\hline $\begin{array}{l}\text { Kalimat yang digunakan dalam } \\
\text { penyajian Modul tidak } \\
\text { memberikan makna ganda } \\
\text { (ambigu) }\end{array}$ & 5 & 4 & 9 & 4,5 \\
\hline
\end{tabular}


Pada Tabel 4 terlihat bahwa rerata hasil penilaian validator terhadap Modul yang dirancang berkisar > 3,20. Menurut Muliyardi (2006: 82) bila rerata hasil validasi bernilai > 3,20 maka perangkat pembelajaran dikategorikan sangat valid. Hasil validasi menggambarkan bahwa penggunaan kalimat pada Modul telah sesuai dengan kaidah bahasa Indinesia yang baik. Kalimat yang digunakan mampu melibatkan kemampuan berfikir logis siswa karena telah disesuaikan dengan tingkat pemahaman dan kapasitas keterbacaan siswa. Hal ini didukung dengan penyajian Modul yang tidak memberikan makna ganda.

Saran-saran yang diberikan validator termuat dalam lembar validasi, diantaranya adalah sebagai berikut.

1. Beberapa tulisan/ pengetikan masih salah.

2. Perbaiki kombinasi warna pada gambar.

3. Penggunaan bahasa Indonesia yang baik dan benar secara umum sudah baik, tetapi perlu diperbaiki sedikit.

4. Sebaiknya jangan memberikan gambar lengkap kepada siswa, coba arahkan siswa membuat sketsa atau gambar sendiri

Berdasarkan saran-saran yang diberikan validator, peneliti sudah melakukan revisi pada Modul sampai Modul bisa dikatakan sangat valid seperti yang sudah diuraikan di atas.

\section{KESIMPULAN}

Modul keliling dan luas bangun datar terdiri dari 3 bagian yaitu Modul 1 dengan pokok bahasan keliling dan luas persegi dan persegi panjang, Modul 2 dengan pokok bahasan keliling dan luas jajargenjang dan segitiga, Modul 3 dengan pokok bahasan keliling dan luas trapesium dan layang-layang.

Modul dikembangkan melalui tahap pendefinisian (define), tahap perancangan (design) dan tahap pengembangan (develop). Berdasarkan hasil penelitian, diperoleh bahwa Modul Pembelajaran keliling dan luas bangun datar memiliki validitas yang sangat valid baik dari aspek materi, penyajian, bahasa dan keterbacaan.

\section{DAFTAR PUSTAKA}

Asmani, J. 2012. Pendidikan Berbasis Keunggulan Lokal. Yogyakarta: DIVA Press

Herumen. 2007. Model Pembelajaran Matematika di Sekolah Dasar, Bandung: PT Remaja Rosdakarya. 
Johnson, Elaine B.2007. Contextual Teaching \& Learning Menjadikan Kegiatan Belajar-Mengajar mengasyikkan dan Bermakna, Bandung: MLC

Karso, dkk. 2009. Pendidikan Matematika 1.Jakarta: Universitas Terbuka

Muhsetyo, Gatot. 2009. Pembelajaran Matematika SD.Jakarta: Universitas Terbuka

Muliyardi. 2006. "Pengembangan Model Pembelajaran Matematika dengan Menggunakan Komik di Kelas I Sekolah Dasar". Disertasi tidak diterbitkan. Surabaya: Pasca Sarjana UNESA.

NCTM (National Council of Teacher of Mathematics). 1998. Priciples and Standards for Schools Mathematics. Reston, Virginia: NCTM.

Rusman.2011. Model-Model Pembelajaran Mengembangkan Profesionalisme Guru. Jakarta: PT RajaGrafindo Persada

Sugiyono. 2008. Metode Penelitian Pendidikan Pendekatan Kuantitatif, Kualitatif, dan $R \& D$, Bandung: Alfabeta

Suherman, Erman dkk. 2003.Strategi Pembelajaran Matematika Kontemporer. Bandung: Universitas Pendidikan Indonesia

Trianto. 2011. Mendesain Model Pembelajaran Inovatif-Progresif, Jakarta: Kencana Prenada Media Group . 2007. Model-Model Pembelajaran Inovatif Berorientasi Konstruktivistik. Jakarta: Prestasi Pustaka

Wena, Made. 2013. Strategi Pembelajaran Inovatif Kontemporer Suatu Tinjauan Konseptual Operasional. Jakarta Timur: PT. Bumi Aksara 